\title{
Assessment of Marginal Adaptation Before and After Thermo-Mechanical Loading and Volumetric Shrinkage: Bulk Fill versus Conventional Composite
}

\author{
Evaluación de la Adaptación Marginal Antes y Después de la Carga Termomecánica \\ y la Contracción Volumétrica: Relleno Bulk-Fill-versus Compuesto Convencional
}

\author{
Fernanda Ferreira de Albuquerque Jassé ${ }^{1}$; Cristiane de Melo Alencar'; \\ Joissi Ferrari Zaniboni'; Aryvelto Miranda Silva1 \& Edson Alves de Campos ${ }^{1}$
}

\begin{abstract}
JASSÉ, F. F. A.; ALENCAR, C. M.; ZANIBONI, J. F.; SILVA, A. M. \& CAMPOS, E. A. Assessment of marginal adaptation before and after thermo-mechanical loading and volumetric shrinkage: bulk fill vs conventional composite. Int. J. Odontostomat., 14(1):60-66, 2019.

ABSTRACT: The objective of the study was to evaluate marginal adaptation of Class II mesial-occlusal-distal (MOD) restorations before and after thermo-mechanical loading and volumetric shrinkage of the bulk-fill vs conventional composite resin. For marginal adaptation assessment, 24 Class II MOD cavities with cervical margins extending $1.0 \mathrm{~mm}$ below (distal) and $1.0 \mathrm{~mm}$ beyond (mesial) the cement-enamel junction were prepared in extracted human molars. The teeth were filled as follows: Group A — bulk-fill with SureFil SDR flow (first increment, $4 \mathrm{~mm}$; second increment, $2 \mathrm{~mm}$ ); Group B — bulk-fill with SureFil SDR flow as a base (first increment, $4 \mathrm{~mm}$ ) and covered with the conventional nanohybrid composite Esthet-X HD (second increment, $2 \mathrm{~mm}$ ); and Group C - incrementally filled with Esthet-X HD. Marginal adaptation was evaluated by scanning electron microscopy before and after thermomechanical loading (240,000 loading cycles and simultaneous 600 thermal cycles). To evaluate volumetric polymerization shrinkage, a semi-spherical mold was filled with the tested composites and placed in an AccuVol device after light curing. Both before and after loading, marginal adaptation in cervical dentin was superior $(p<0.05)$ for Groups A and B compared with Group C. In cervical enamel, Group B showed better marginal adaptation than Group C, and Group A presented intermediary results, between Groups B and C. Furthermore, bulk-fill flow resulted in greater shrinkage than Esthet-X HD. A significant improvement of marginal adaptation was observed when bulkfill flow was used instead of conventional composite resin both before and after thermomechanical loading. However, the bulk-fill flow presented higher volumetric polymerization shrinkage than the conventional composite.
\end{abstract}

KEY WORDS: composite resins, dental marginal adaptation, dental cavity preparation, polymerization.

\section{INTRODUCTION}

The development of new resin-based composite (RBC) materials has aimed to decrease polymerization shrinkage stress. According to Kleverlaan \& Feilzer (2005), volumetric shrinkage varies from $1 \%-3 \%$ for packable RBCs and reaches up to $6 \%$ for flowable RBCs during polymerization of dimethacrylate-based composites. Shrinkage stress is highly dependent on a combination of material properties and cavity preparation design (Davidson \& Feilzer, 1997). It may affect marginal adaptation through gap formation, both internally and at the cavosurface margins, thus generating clinical problems, such as microleakage, marginal staining, recurrent caries, postoperative sensitivity, and even irritation of pulp tissue (Davidson \& Feilzer; Campos et al., 2014). Several strategies to reduce shrinkage stress have been proposed in the literature. They include incremental layering techniques (Lutz et al., 1986), varying light-curing protocols, the application of a base with low-modulus resin to absorb shrinkage stress, the use of ceramic inserts, and C-factor modification (Cunha et al., 2003). However, these strategies have disadvantages, such as loss of clinical time and technical sensitivity (Gregor et al., 2013).

\footnotetext{
${ }^{1}$ Department of Restorative Dentistry, Araraquara School of Dentistry, UNESP Univ Estadual Paulista, Araraquara, Brazil.

This word was financed by Coordenação de Aperfeiçoamento de Pessoal de Nível Superior - CAPES, Brazil - Finance Code 001.
} 
Despite the efforts of dental-material companies, a low-shrinkage RBC material allowing perfect marginal sealing has yet to be created. Bulk-fill flowable resin was recently developed as a result of ongoing efforts to simplify clinical restorative treatment of deep and high C-factor cavities, as well as for dentin replacement. SureFil SDR flow, as it was introduced on the American market, is recommended by its manufacturer to be used in $4 \mathrm{~mm}$ thickness increments because of its reduced polymerization stress. In addition, it needs to be veneered with $2 \mathrm{~mm}$ of a conventional resin composite (Shahidi et al., 2017).

Materials based on stress decreasing resin (Bulkfill) technology have the dynamics of their polymerization reaction modified by incorporating a photoactive group in a urethane-based methacrylate resin. Compared with conventional methacrylate-based resins, the modified urethane dimethacrylate resin presents a $60 \%$ to $70 \%$ decrease in shrinkage stress for unfilled resin (Jin et al., 2009). The photoinitiator incorporated into the resin allows a slow curing rate. Jin et al. suggested that a lower curing stress could also be observed in filled compositions.

Most studies that evaluated various properties of bulk-fill have obtained satisfactory results when compared with those for conventional resins (Roggerndorf et al., 2011; Salerno et al., 2011; Moorthy et al., 2012; Nazari et al., 2013a,b; llie et al., 2013; Van Ende et al., 2013; Campos et al.; El-Damanhoury \& Platt, 2014; Furness et al., 2014). However, due to relatively recent breeding of bulkfill resins, long-term randomized clinical trials to assess clinical quality of the materials are scarce. In this context, long term in vitro analyzes are considered valid simulations of the oral conditions of load and temperature. Thus, the aim of this study was to compare a low-shrinkage flowable resin-based composite and a conventional nanohybrid $\mathrm{RBC}$ in terms of polymerization shrinkage and cervical marginal quality before and after thermomechanical loading, using the same adhesive system. The tested null hypotheses were: (1) there is no significant difference in cervical marginal adaptation between the tested materials, both before and after thermomechanical loading; and (2) there is no significant difference in volumetric polymerization shrinkage between the tested materials when measuring.

\section{MATERIAL AND METHOD}

Ethical aspects. This study was evaluated and approved by the Committee of Ethics in Research on Human Beings of the local university under the $36 / 11$ protocol. The teeth were obtained by signing a donation term and all participants signed an Informed Consent Form prior to participating in the study, in full compliance with Declaration of Helsinki.

Cavity preparation. Twenty-four extracted, intact, noncarious, unrestored human molars stored in $0.1 \%$ thymol solution were selected. Teeth were obtained from the human tooth bank of the Dental Medicine Section of the University of Geneva following the requirements of the local ethical committee. Teeth were debrided of any plaque or calculus deposits with a hand-scaler and examined to ensure that they were free of defects.

Table I. Summary of the materials used in this study.

\begin{tabular}{|c|c|c|c|c|}
\hline Brand name & Type & Composition & $\begin{array}{c}\text { Filler } \\
\text { Wt\% / Vol\% }\end{array}$ & Manufacturer \\
\hline $\begin{array}{l}\text { SureFil } \\
\text { SDR }^{\mathrm{TM}} \text { flow }\end{array}$ & $\begin{array}{l}\text { Flowable bulk fill } \\
\text { composite resin }\end{array}$ & $\begin{array}{l}\text { Ba-Al-F-B silicate glass, Sr-A-F silicate } \\
\text { glass, Modified UDMA, EBPADMA, } \\
\text { TEGDMA. Camphorquinone photo-initiator } \\
\text { (CQ), butylated hydroxytoluene (BHT), UV } \\
\text { stabilizer, Titanium dioxide, Iron oxide } \\
\text { pigments. }\end{array}$ & $68 / 44 \%$ & $\begin{array}{c}\text { Dentsply DeTrey, } \\
\text { Konstanz, } \\
\text { Germany }\end{array}$ \\
\hline Esthet-X ${ }^{\prime \prime \prime}$ HD & $\begin{array}{c}\text { Conventional } \\
\text { nanohybrid } \\
\text { composite resin }\end{array}$ & $\begin{array}{l}\text { Bis-GMA, B is-EMA, TEGDMA, } \\
\text { Camphorquinone photo-initiator (CQ), UV } \\
\text { stabilizer, pigments. Combination of } \\
\text { particulate fluoro-barium-borosilicate glass } \\
\text { with a mean particle size below 1_m and } \\
\text { silica nanoparticles of } 0,04 \text { m. }\end{array}$ & $77 / 60 \%$ & $\begin{array}{l}\text { Dentsply Caulk, } \\
\text { Milford, USA }\end{array}$ \\
\hline Xeno $^{\mathrm{TM}} \mathrm{V}$ & $\begin{array}{l}\text { One-component } \\
\text { self-etching } \\
\text { adhesive }\end{array}$ & $\begin{array}{l}\text { Bifunctional acrylic amides, Acrylamido } \\
\text { alkylsuloonic acid, "inverse" functionalized } \\
\text { phosphoric acid ester, Acrylic acid, } \\
\text { Camphorquinone, Coinitiator, Butylated } \\
\text { benzenediol, Water, Tert-butanol. }\end{array}$ & ---- & $\begin{array}{c}\text { Dentsply DeTrey, } \\
\text { Konstanz, } \\
\text { Germany }\end{array}$ \\
\hline
\end{tabular}

UDMA: urethane dimethacrylate; EBPADMA: ethoxylated Bisphenol A dimethacrylate; TEGDMA: ttriethyleneglycol dimethacrylate; BisEMA: Bisphenol A polyethylene glycol diether dimethacrylate; Bis-GMA: Bisphenol A dimethacrylate. 
JASSÉ, F. F. A.; ALENCAR, C. M.; ZANIBONI, J. F.; SILVA, A. M. \& CAMPOS, E. A. Assessment of marginal adaptation before and after thermo-mechanical loading and volumetric shrinkage: bulk fill vs conventional composite. Int. J. Odontostomat., 14(1):60-66, 2019.

All teeth were mounted in the centre of custommade metallic holders and fixed with a light-curing composite. The root bases were then coated with a cold-polymerizing resin to complete the stabilization of specimens. Standardized large class II MOD cavities were prepared with parallel walls and bevelled enamel beyond (mesial) and $1.0 \mathrm{~mm}$ below (distal) the cementum-enamel junction. The overall dimensions and depth of the cavities are illustrated in Figure 1. Cavities were prepared using a high-speed handpiece with strong air-water spray with $80-\mathrm{mm}$ diamond burs and 40-mm finishing diamond burs. The dimensions of the preparations were monitored using a calliper and a periodontal probe. All the teeth were randomly divided into three experimental groups $(n=8)$.

Restorative procedure. The materials used in this study are listed in Table I. All restorations were made by the same operator. A single-component self-etch dental adhesive was applied according to manufacturer's instructions in all groups. It was then light-cured for $20 \mathrm{~s}$ using a light-emitting diode (LED) curing light with an output irradiance of approximately $1100 \mathrm{~mW} / \mathrm{cm}^{2}$. Throughout the experiment, the light output from the lighting control unit (LCU) was verified by a radiometer. Then, cavities were surrounded with a metal matrix band and restored as follows (Table II).
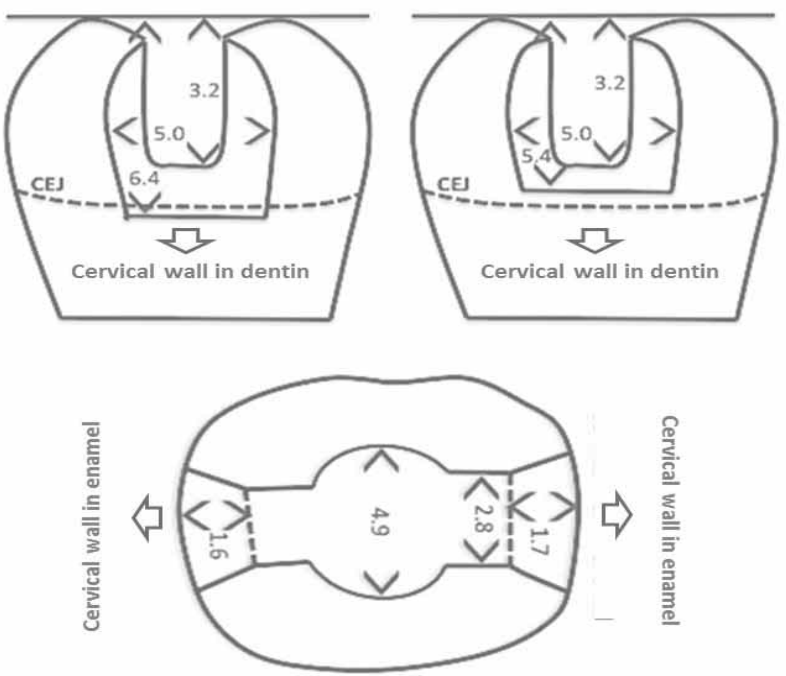

Fig. 1. The overall dimensions and depth of the cavities. margins. Proximal margins were prepared $1.0 \mathrm{~mm}$

* Group A: The composite resin SureFil SDR flow was dispensed directly into the cavity preparation with the aid of a syringe under slow and constant pressure, in one 4-mm bulk increment, and light-cured for $20 \mathrm{~s}$. The remainder of the cavity was filled with another bulk increment of the same composite.

* Group B: Teeth were restored according to manufacturer's recommendations. The composite resin SureFil SDR flow was dispensed directly into the cavity preparation with the aid of a syringe under slow and constant pressure, in one 4-mm bulk increment, and light-cured for $20 \mathrm{~s}$. The remainder of the cavity was filled with the nanohybrid composite Esthet-X HD through an incremental technique and light-cured for $20 \mathrm{~s}$.

* Group C: Cavities were filled through an incremental technique (oblique increments of $\sim 2 \mathrm{~mm}$ ) with the nanohybrid composite Esthet-X HD. Each increment was light-cured separately for $20 \mathrm{~s}$.

Immediately after light curing, occlusal margins were finished with fine diamond burs, and proximal margins were finished and polished with flexible aluminium-oxide disks.

Thermomechanical cycling and evaluation of marginal adaptation. After the procedures were finished, epoxy resin replicas of each restoration were obtained by using a polyvinylsiloxane material.

After storage for $24 \mathrm{~h}$ in water at $37^{\circ} \mathrm{C}$, thermomechanical loading was carried out in a computer-controlled chewing machine. All specimens were submitted to 240,000 mechanical loading cycles. Load was transferred to the center of the occlusal surface at a maximum of $49 \mathrm{~N}$ and frequency of 1.7 $\mathrm{Hz}$. Load was applied by using natural cusps taken from extracted human molars. Simultaneously, thermocycling was performed in flushing water with temperatures changing 600 times from $5^{\circ} \mathrm{C}$ to $50^{\circ} \mathrm{C}$, with a dwell time of 2 min.

After chewing simulation cycles, a new set of epoxy resin replicas was obtained. All replicas were mounted on aluminum stubs, gold-coated, and examined under

Table II. Experimental groups divided according to restorative technique.

\begin{tabular}{|c|c|c|}
\hline Group & First increment (4mm thick) & Second increment (2mm thick) \\
\hline$A$ & SureFil $^{\circledR}$ SDR $^{\text {TM }}$ flow & SureFil $^{\circledR}$ SDR $^{\text {TM }}$ flow \\
\hline B & SureFil $^{\circledR}$ SDR $^{\mathrm{TM}}$ flow & EsthetX ${ }^{\mathrm{TM}} \mathrm{HD}$ \\
\hline C & Esthet $X^{\mathrm{TM}} \mathrm{HD}$ & 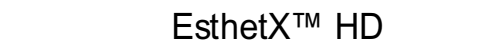 \\
\hline
\end{tabular}
a scanning electron microscope at a standard 200' magnification. By means of computer-assisted quantitative margin analysis, the marginal quality, before and after 
thermomechanical loading, was expressed as the percentage of continuous margin for the total margin length (Krejci et al., 2003).

Volumetric polymerization shrinkage. The volumetric shrinkage of the tested composite resins was evaluated using a video-imaging device, operating in the single-view mode at room temperature $\left(23^{\circ} \mathrm{C} /\right.$ $\left.24^{\circ} \mathrm{C}\right)$. Specimens $(\mathrm{n}=5)$ were made by placing $15 \mathrm{ml}$ $( \pm 1)$ of the tested resins into a semi-spherical mould that was moved to a polytetrafluoroethylene pedestal (4.2-mm diameter) in front of the camera of the machine. The obtained image was captured and digitized by AccuVol Bisco software (MIOD Detection) and, after the flow of the material for $2 \mathrm{~min}$, the perimeter of the samples was measured by a virtual dotted line. The measured size was stored in the program representing the initial sample volume. Then, the composite was cured for 20 s (using LED LCU Bluephase G2, Ivoclar Vivadent) with the curing tip placed $5 \mathrm{~mm}$ from the top surface of the composite. Five minutes after light curing, a volume shrinkage image was recorded. This wait time allowed the temperature to decrease to room temperature.

Statistical analysis. For marginal adaptation values, the dependent variables 'restorative protocols' and 'loading intervals' were statistically analyzed using twoway analysis of variance (ANOVA) and Sidak's post hoc test at a $5 \%$ level of significance. For polymerization shrinkage, statistical analysis was performed using ANOVA and Tukey's post hoc test at a $5 \%$ level of significance.

\section{RESULTS}

Marginal adaptation. The results for cervical dentin and enamel marginal adaptation, expressed as percentages of continuous margins (\%CM), are shown in Table III. When considering dentin margin length, the lowest values of \%CM were observed in Group C (Esthet-X only), both before and after thermomechanical loading. The same occurred for enamel margin length. Insignificant differences were noted between Groups A and B both for enamel and dentin margins. Most of the tested groups did not present significant differences before and after thermomechanical loading, both for enamel and dentin margins. The only exception was observed for Group A in cervical enamel.

Mean scores of cervical enamel integrity varied from $25.93 \%$ (Group B) to $11.39 \%$ (Group C) before thermomechanical loading and from $18.73 \%$ (Group B) to $0.0 \%$ (Group C) after thermomechanical loading. For cervical dentin, mean values varied from $65.81 \%$ (Group A) to $5.76 \%$ (Group C) and from $53.40 \%$ (Group A) to $0.0 \%$ (Group C) before and after thermomechanical loading, respectively.

Volumetric polymerization shrinkage. Table IV presents a summary of the volumetric polymerization shrinkage of the composite resins investigated in this study. Esthet-X exhibited statistically significantly lower $(p<0.05)$ shrinkage values in comparison with bulk-fill resin.

Table IV. Mean values (\%) ( \pm standard deviation) of volumetric polymerization shrinkage of the tested composites (ANOVA and Tukey test, $\mathrm{p}<0,05)$.

\begin{tabular}{ccc}
\hline & Esthet-X & SDR \\
\hline Mean & $2,710 \mathrm{~A}$ & $4,942 \mathrm{~B}$ \\
SD & $( \pm 0,287)$ & $( \pm 0,660)$ \\
\hline
\end{tabular}

${ }^{*}$ Different superscript letters within line mean $p<0.05$.

Table III. Cervical marginal adaptation in enamel and dentin expressed as percentages of continuous margins $[(\operatorname{mean} \%)$ ( \pm standard deviation)], using different restoring protocols, before and after thermomechanical loading.

\begin{tabular}{cllll}
\hline \multirow{2}{*}{ GROUP } & \multicolumn{2}{c}{ Cervical Enamel } & \multicolumn{2}{c}{ Cervical Dentin } \\
\cline { 2 - 5 } & \multicolumn{1}{c}{ Before loading } & \multicolumn{1}{c}{ After loading } & \multicolumn{1}{c}{ Before loading } & After loading \\
\hline $\mathrm{A}$ & $21,71( \pm 11,56) \mathrm{ABa}$ & $7,86( \pm 4,70) \mathrm{ABb}$ & $65,81( \pm 15,73) \mathrm{Aa}$ & $53,40( \pm 22,72) \mathrm{Aa}$ \\
$\mathrm{B}$ & $25,93( \pm 15,22) \mathrm{Aa}$ & $18,73( \pm 11,54) \mathrm{Aa}$ & $52,27( \pm 23,30) \mathrm{Aa}$ & $39,28( \pm 16,71) \mathrm{Aa}$ \\
$\mathrm{C}$ & $11,39( \pm 4,87) \mathrm{Ba}$ & $0( \pm 0) \mathrm{Ba}$ & $5,76( \pm 5,60) \mathrm{Ba}$ & $0( \pm 0) \mathrm{Ba}$ \\
\hline
\end{tabular}

*Means with same capital letters in columns are not statistically different at $p=0.05$. Means with same lower case letters in lines mean $p>0.05$. 
JASSÉ, F. F. A.; ALENCAR, C. M.; ZANIBONI, J. F.; SILVA, A. M. \& CAMPOS, E. A. Assessment of marginal adaptation before and after thermo-mechanical loading and volumetric shrinkage: bulk fill vs conventional composite. Int. J. Odontostomat., 14(1):60-66, 2019.

\section{DISCUSSION}

The results showed that the tested materials exhibited unsatisfactory cervical marginal adaptation both before and after thermomechanical loading, mostly in enamel. Besides the unsatisfactory results, groups that used the bulk-fill composite demonstrated statistically better cervical marginal adaptation than the group where only the conventional composite was applied. Therefore, the first null hypothesis was rejected.

The unsatisfactory results obtained in enamel were probably caused by the use of one-bottle selfetching adhesive without prior application of phosphoric acid. The importance of selective etching in enamel margins when self-etching adhesive systems are used to obtain enamel adhesion resistant to ageing was shown in previous studies (Van Meerbeek et al., 2003; Frankenberger et al., 2008; Roggendorf et al., 2011; Van Meerbeek et al., 2011; Peumans et al., 2012; Campos et al.) and it was reaffirmed by the present study.

Considering the groups where bulk-fill was used, the results obtained in dentin are comparable with those of Campos et al., where a 'gold standard' etch-andrinse adhesive was applied. The methodology of the latter study was similar to that of this study. Thus, the use of one-bottle self-etching adhesive Xeno $V$ does not impair the results for dentin substrate.

The clinical success of novel restorative materials requires long periods of use by general practitioners to be verified. Although in vivo tests remain the gold standard way to assess the performance of dental materials, in vitro tests are also a valuable way to characterize new materials before clinical long-term results become available (Garcia-Godoy et al., 2010; Kramer et al., 2011; Peumans et al.; Salerno et al.). In this study, the cervical marginal integrity of the tested materials was evaluated before and after thermomechanical loading to simulate long-term fatigue in an oral cavity.

Pecie et al. (2013) affirmed through polymerization stress maps that the cervical zone is the dental region of maximum stress accumulation, with the dentin-restoration interface being the most problematic area for adhesion. Cervical marginal adaptation was assessed in the present study considering the problems that clinicians face when restoring this specific area in class II cavities. In contrast to the above-mentioned study, the present research found cervical enamel to be the problematic area, probably because of the adhesive system selected. Although negative results were observed for all tested groups, groups in which bulk-fill was used showed significantly better marginal adaptation values both before and after thermomechanical loading. The results suggest that bulk-fill favors marginal adaptation because of the flow in the proximal boxes.

The claimed-low-shrinkage flowable composite bulk-fill presented a higher percentage of volumetric polymerization shrinkage than the conventional composite Esthet-X HD. Therefore, the second null hypothesis was also rejected. Shahidi et al. also used an AccuVol device to measure the polymerization shrinkage of bulk-fill and obtained a value of $3.1 \%$ shrinkage, somewhat lower than that found in the present study. However, these authors pointed out that, despite polymerization shrinkage, marginal stress may be reduced by increased flowing during bulk filling. Another study agrees with the present study, obtaining greater shrinkage values for flowable materials in comparison with nanohybrid material (Garcia et al., 2014). A direct relationship between shrinkage and the amount of organic matrix present in the composite resin was observed. Thus, the higher resin content of the flowable composite is responsible for the higher volumetric shrinkage observed (Hughes et al., 2019). Therefore, even though bulk-fill presents higher volumetric shrinkage than Esthet-X HD, it can be assumed that the slow rate of polymerization promoted by the new modulator can reduce shrinkage stress. This assumption is supported by the results obtained in a study where bulk-fill flowable bases significantly reduced cuspal deflection in comparison with a conventional composite used through the oblique incremental filling technique (Moorthy et al.).

Several authors recommend the use of a flowable composite as a stress-absorbing liner or base, suggesting that its relatively low modulus of elasticity and deformation ability can help decrease polymerization shrinkage stress (Davidson \& Feilzer; Braga \& Ferracane, 2004; Ferracane, 2008). However, conflicting results have been reported regarding the action of flowable composite materials as stress breakers or adaptation promoters (Oliveira et al., 2010; Meereis et al., 2018).

Although nominal values obtained for cervical dentin using only bulk-fill have been higher, the manufacturer's recommendation to overlay the bulk- 
fill base material must be followed. A study that evaluated the mechanical performance of bulk-fill composites showed that the modulus of elasticity and hardness of bulk-fill resin were considerably lower than those of conventional nanohybrid and microhybrid resins (Ilie et al.). Thus, these features need to be compensated for by the better mechanical properties of conventional composites.

\section{CONCLUSIONS}

A significant improvement of marginal adaptation was observed when bulk-fill flow was used instead of conventional composite resin both before and after thermomechanical loading. However, the bulk-fill flow presented higher volumetric polymerization shrinkage than the conventional composite. The results of this study confirm that the bulk-fill flow resin tested has characteristics comparable or superior to those of conventional resin regarding cervical marginal adaptation. However, only long-term clinical trials can confirm the clinical success of the material.

JASSÉ, F. F. A.; ALENCAR, C. M.; ZANIBONI, J. F.; SILVA, A. M. \& CAMPOS, E. A. Evaluación de la adaptación marginal antes y después de la carga termomecánica y la contracción volumétrica: Relleno Bulk-Fill- versus compuesto convencional. Int. J. Odontostomat., 14(1):60-66, 2019.

RESUMEN: El objetivo de este trabajo consistió en evaluar la adaptación marginal de las restauraciones mesiales-oclusales-distales (MOD) de Clase II antes y después de la carga termo-mecánica y la contracción volumétrica de la carga compuesta de resina "bulk-fill" en comparación con resina convencional. Para la evaluación de adaptación, se prepararon 24 cavidades MOD de Clase II en molares humanos extraídos, los que se restauraron de la siguiente manera: Grupo A: restaurado con resina fluida Bulk-Fill SureFilSDR (primer incremento, $4 \mathrm{~mm}$; segundo incremento, $2 \mathrm{~mm}$ ); Grupo B: restaurado con resina fluida Bulk-Fill SureFil SDR (primer incremento, $4 \mathrm{~mm}$ ) y cubierto con resina compuesta nanohíbrida Esthet-X HD (segundo incremento, $2 \mathrm{~mm}$ ); y Grupo C - rellenado incrementalmente con Esthet-X HD. La adaptación marginal se evaluó mediante microscopía electrónica de barrido antes y después de la carga termomecánica (240.000 ciclos de carga y 600 ciclos térmicos simultáneos). Para evaluar la contracción volumétrica de la polimerización, se llenó un molde semiesférico con los compuestos probados y se colocó en un dispositivo AccuVol después del fotopolimerización. Tanto antes como después de la carga, la adaptación marginal en la dentina cervical fue superior $(p<0,05)$ para los grupos $A$ y $B$ en comparación con el grupo C. En el esmalte cervi- cal, el grupo B mostró una mejor adaptación marginal que el grupo C, y el grupo A presentó resultados intermedios, entre Grupos B y C. Se observó una mejora significativa de la adaptación marginal al utilizar la resina fluida Bulk-Fill en lugar de resina compuesta convencional tanto antes como después de la carga termomecánica. Sin embargo, la resina fluida 'Bulk-Fill' presentó una mayor contracción volumétrica de polimerización que el compuesto convencional.

PALABRAS CLAVE: Resinas compuestas, Adaptación marginal dental, Preparación de cavidades dentales, Polimerización.

\section{REFERENCES}

Braga, R. R. \& Ferracane, J. L. Alternatives in polymerization contraction stress management. Crit. Rev. Oral Biol. Med., 15(3):176-84, 2004.

Campos, E. A.; Ardu, S.; Lefever, D.; Jassé, F. F.; Bortolotto, T. \& Krejci, I. Marginal adaptation of class II cavities restored with bulk-fill composites. J. Dent., 42(5):575-81, 2014.

Cunha, L. G.; Sinhoreti, M. A.; Consani, S. \& Sobrinho, L. C. Effect of different photoactivation methods on the polymerization depth of a light-activated composite. Oper. Dent., 28(2):155-9, 2003.

Davidson, C. L. \& Feilzer, A. J. Polymerization shrinkage and polymerization shrinkage stress in polymer-based restoratives. J. Dent., 25(6):435-40, 1997.

El-Damanhoury, H. \& Platt, J. Polymerization shrinkage stress kinetics and related properties of bulk-fill resin composites. Oper. Dent., 39(4):374-82, 2014.

Ferracane, J. L. Buonocore Lecture. Placing dental composites--a stressful experience. Oper. Dent., 33(3):247-57, 2008.

Frankenberger, R.; Lohbauer, U.; Roggendorf, M. J.; Naumann, M. \& Taschner, M. Selective enamel etching reconsidered: better than etch-and-rinse and self-etch? J. Adhes. Dent., 10(5):33944, 2008.

Furness, A.; Tadros, M. Y.; Looney, S. W. \& Rueggeberg, F. A. Effect of bulk/incremental fill on internal gap formation of bulk-fill composites. J. Dent., 42(4):439-49, 2014.

Garcia-Godoy, F.; Krämer, N.; Feilzer, A. J. \& Frankenberger, R. Longterm degradation of enamel and dentin bonds: 6-year results in vitro vs. in vivo. Dent. Mater., 26(11):1113-8, 2010.

Garcia, D.; Yaman, P.; Dennison, J. \& Neiva, G. Polymerization shrinkage and depth of cure of bulk fill flowable composite resins. Oper. Dent., 39(4):441-8, 2014.

Gregor, L.; Bortolotto, T.; Feilzer, A. J. \& Krejci, I. Shrinkage kinetics of a methacrylate- and a silorane-based resin composite: effect on marginal integrity. J. Adhes. Dent., 15(3):245-50, 2013.

Hughes, K. O.; Powell, K. J.; Hill, A. E.; Tantbirojn, D. \& Versluis, A. Delayed Photoactivation of Dual-cure Composites: Effect on Cuspal Flexure, Depth-of-cure, and Mechanical Properties. Oper. Dent., 44(2):E97-E104, 2019.

Ilie, N.; Bucuta, S. \& Draenert, M. Bulk-fill resin-based composites: an in vitro assessment of their mechanical performance. Oper. Dent., 38(6):618-25, 2013

Jin, X.; Bertrand, S. \& Hammesfahr, P. D. New radically polymerizable resins with remarkably low curing stress. J. Dent. Res., 88(Spec. Iss. A):1651, 2009.

Kleverlaan, C. J. \& Feilzer, A. J. Polymerization shrinkage and contraction stress of dental resin composites. Dent. Mater., 21(12):1150-7, 2005. 
Kramer, N.; García-Godoy, F.; Reinelt, C.; Feilzer, A. J. \& Frankenberger, R. Nanohybrid vs. fine hybrid composite in extended Class II cavities after six years. Dent. Mater., 27(5):45564, 2011.

Krejci, I.; Duc, O.; Dietschi, D. \& de Campos, E. Marginal adaptation, retention and fracture resistance of adhesive composite restorations on devital teeth with and without posts. Oper. Dent., 28(2):127-35, 2003.

Lutz, E.; Krejci, I. \& Oldenburg, T. R. Elimination of polymerization stresses at the margins of posterior composite resin restorations: a new restorative technique. Quintessence Int., 17(12):777-84, 1986.

Meereis, C. T. W.; Münchow, E. A.; de Oliveira da Rosa, W. L.; da Silva, A. F. \& Piva, E. Polymerization shrinkage stress of resinbased dental materials: A systematic review and meta-analyses of composition strategies. J. Mech. Behav. Biomed. Mater., 82:268-81, 2018.

Moorthy, A.; Hogg, C. H.; Dowling, A. H.; Grufferty, B. F.; Benetti, A. R. \& Fleming, G. J. Cuspal deflection and microleakage in premolar teeth restored with bulk-fill flowable resin-based composite base materials. J. Dent., 40(6):500-5, 2012

Nazari, A.; Sadr, A.; Saghiri, M. A.; Campillo-Funollet, M.; Hamba, H.; Shimada, Y.; Tagami, J. \& Sumi, Y. Non-destructive characterization of voids in six flowable composites using sweptsource optical coherence tomography. Dent. Mater., 29(3):27886, 2013a.

Nazari, A.; Sadr, A.; Shimada, Y.; Tagami, J. \& Sumi, Y. 3D assessment of void and gap formation in flowable resin composites using optical coherence tomography. J. Adhes. Dent., 15(3):237-43, 2013b

Oliveira, L. C. A.; Duarte Jr, S.; Araujo, C. A. \& Abrahão, A. Effect of low-elastic modulus liner and base as stress-absorbing layer in composite resin restorations. Dent. Mater., 26(3):e159-69, 2010.

Pecie, R.; Onisor, I.; Krejci, I. \& Bortolotto, T. Marginal adaptation of direct class II composite restorations with different cavity liners. Oper. Dent., 38(6):E210-20, 2013.

Peumans, M.; De Munck, J.; Van Landuyt, K. L.; Poitevin, A.; Lambrechts, P. \& Van Meerbeek, B. A 13-year clinical evaluation of two three-step etch-and-rinse adhesives in non-carious classV lesions. Clin. Oral Investig., 16(1):129-37, 2012.

Roggendorf, M. J.; Krämer, N.; Appelt, A.; Naumann, M. \& Frankerberger, R. Marginal quality of flowable 4-mm base vs. conventionally layered resin composite. J. Dent., 39(10):643-7, 2011.

Salerno, M.; Derchi, G.; Thorat, S.; Ceseracciu, L.; Ruffilli, R. \& Barone, A. C. Surface morphology and mechanical properties of new-generation flowable resin composites for dental restoration. Dent. Mater. 27(12):1221-8, 2011.

Shahidi, C.; Krejci, I. \& Dietschi, D. In vitro evaluation of marginal adaptation of direct class II composite restorations made of different "low-shrinkage" systems. Oper. Dent., 42(3):273-83, 2017.

Van Ende, A.; De Munck, J.; Van Landuyt, K. L.; Poitevin, A.; Peumans, M. \& Van Meerbeek, B. Bulk-filling of high C-factor posterior cavities: effect on adhesion to cavity-bottom dentin. Dent. Mater., 29(3):269-77, 2013.

Van Meerbeek, B.; De Munck, J.; Yoshida, Y.; Inoue, S.; Vargas, M.; Vijay, P.; Van Landuyt, K.; Lambrechts, P. \& Vanherle, G. Buonocore memorial lecture. Adhesion to enamel and dentin: current status and future challenges. Oper. Dent., 28(3):215-35, 2003.

Van Meerbeek, B.; Yoshihara, K.; Yoshida, Y.; Mine, A.; De Munck, J. \& Van Landuyt, K. L. State of the art of self-etch adhesives. Dent. Mater., 27(1):17-28, 2011.
Corresponding author:

Fernanda Ferreira de Albuquerque Jassé

Rua Humaitá, 1680

Araraquara - SP

BRAZIL

Email: fernandajasse@hotmail.com

Received: 22-07-2019

Accepted: 22-08-2019 